\title{
Simple interface of high-performance liquid chromatography-atomic fluorescence spectrometry hyphenated system for speciation of mercury based on photo-induced chemical vapour generation with formic acid in mobile phase as reaction reagent
}

\author{
Yongguang Yin, Jingfu Liu, Bin He, Jianbo Shi, Guibin Jiang* \\ State Key Laboratory of Environmental Chemistry and Ecotoxicology, Research Center for Eco-Environmental Sciences, \\ Chinese Academy of Sciences, P.O. Box 2871, Beijing 100085, China
}

Received 16 August 2007; received in revised form 13 December 2007; accepted 18 December 2007

Available online 24 December 2007

\begin{abstract}
Photo-induced chemical vapour generation (CVG) with formic acid in mobile phase as reaction reagent was developed as interface to online couple HPLC with atomic fluorescence spectrometry for the separation and determination of inorganic mercury, methylmercury (MeHg), ethylmercury $(\mathrm{EtHg})$ and phenylmercury $(\mathrm{PhHg})$. In the developed procedure, formic acid in mobile phase was used to decompose organomercuries and reduce $\mathrm{Hg}^{2+}$ to mercury cold vapour under UV irradiation. Therefore, no post-column reagent was used and the flow injection system in traditional procedure is omitted. A number of operating parameters including $\mathrm{pH}$ of mobile phase, concentration of formate, flow rate of mobile phase, length of PTFE reaction coil, flow rate of carrier gas and $\mathrm{Na}_{2} \mathrm{~S}_{2} \mathrm{O}_{3}$ in sample matrix were optimized. The limits of detection at the optimized conditions were $0.085,0.033,0.029$ and $0.038 \mu \mathrm{g} \mathrm{L}^{-1}$ for inorganic mercury, $\mathrm{MeHg}$, EtHg and $\mathrm{PhHg}$, respectively. The developed method was validated by determination of certified reference material DORM-2 and was further applied in analyses of seafood samples from Yantai port, China. The UV-CVG with formic acid simplifies the instrumentation and reduces the analytical cost significantly.
\end{abstract}

(C) 2007 Elsevier B.V. All rights reserved.

Keywords: Speciation; Mercury; High-performance liquid chromatography; Atomic fluorescence spectroscopy; Photo-induced chemical vapour generation; Formic acid

\section{Introduction}

Compared with direct liquid-sample introduction, chemical vapour generation (CVG), as a liquid-sample introduction technique, including hydride generation, alkylation, halide generation, metal carbonyls or cold elemental vapour generation, can separate the analyte from the complex matrix, reduce interferences and improve detection sensitivity and selectivity [1]. Thus, CVG have many advantages in real sample analysis. CVG is widely used as a liquid-sample introduction technique for atomic spectroscopy and as interface for HPLC and atomic spectroscopy such as atomic absorption spectrometry (AAS) [2-4], inductively coupled plasma mass spectrometry (ICP-

\footnotetext{
* Corresponding author. Fax: +86 1062849179.

E-mail address: gbjiang @ rcees.ac.cn (G. Jiang).
}

MS) [5,6], atomic fluorescence spectrometry (AFS) [7-14] and atomic emission spectrometry (AES) [15]. Hydride or cold elemental vapour generation, as interface of HPLC and atomic spectroscopy is widely used for speciation of $\mathrm{Hg}, \mathrm{Sn}, \mathrm{Se}, \mathrm{As}$ and other metals. The mostly used reagent for hydride or cold elemental vapour generation is potassium or sodium borohydride. But reduction by potassium or sodium borohydride has some disadvantages such as unstable reagent and interference of transitional metal ions. In the past years, photo-induced reduction or CVG was reported as a technique for remediation of heavy metal contamination [16-19]. This chemical vapour generation, in presence of organic acid under UV irradiation, was also coupled with atomic spectrometry for the analysis of selenium, mercury and other metal or non-metal element [20,21], which proved that the green, simple and selective UV-CVG is a useful new alternative to the conventional $\mathrm{KBH}_{4}$ system. Further, a UV/nano- $\mathrm{TiO}_{2}$ vapour generation device with formic acid 
was adopted for coupling HPLC with ICP-MS for the determination of inorganic $\mathrm{Se}(\mathrm{IV})$ and $\mathrm{Se}(\mathrm{VI})$ [22]. Also, direct vapour generation of mercury species on nano- $\mathrm{TiO}_{2}$ under UV irradiation in the presence of a formic acid and sodium formate mixture was developed as interface of HPLC-AFS for speciation of mercury [23]. Based on photo-induced CVG with formic acid instead of the conventional $\mathrm{K}_{2} \mathrm{~S}_{2} \mathrm{O}_{8} / \mathrm{KBH}_{4}$ system, we recently developed an on-line coupled HPLC-AFS procedure for the speciation of inorganic mercury, methylmercury ( $\mathrm{MeHg}$ ), ethylmercury (EtHg) and phenylmecury (PhHg) [24]. This procedure was based on a post-column mix and reaction with formic acid. Under UV irradiation, the decomposition of organic mercury species and reduction of $\mathrm{Hg}^{2+}$ could be completed in one step [25] with this proposed photo-induced CVG system without nano- $\mathrm{TiO}_{2}$ catalyst.

In this present work, we describe an on-line HPLC-AFS hyphenated system for mercury speciation with formic acid in mobile phase as reaction reagent for UV-CVG. Mercury species separated by HPLC was decomposed and reduced to mercury cold vapour under UV irradiation with the formic acid added in mobile phase. Because formic acid in the mobile phase was used as reaction reagent for UV-CVG, no other post-column reagent was used and the flow injection system in conventional procedure is not necessary, which dramatically simplified the hyphenated system. Optimum conditions for the new photochemical vapour generation procedure were studied, and the developed method was validated by determination of certified reference material.

\section{Experimental}

\subsection{Instrumentation}

Samples were injected by a Rheodyne model 7725i injection valve with a $100 \mu \mathrm{L}$ sample loop (Rheodyne, Cotati, CA, USA) and the mobile phase was delivered by a P680 HPLC pump (Dionex, Sunnyvale, CA, USA). The HPLC separation of mercury species was achieved by using a Shim-pack CLCODS column ( $15 \mathrm{~cm}$ length, $6 \mathrm{~mm}$ I.D., $5 \mu \mathrm{m}$ diameter particles, Shimadzu, Japan).

Chromatographic eluent entered into a polytetrafluoroethylene (PTFE) tube (0.5 m length, $0.8 \mathrm{~mm}$ I.D., $1.2 \mathrm{~mm}$ O.D.) wrapped around a $20 \mathrm{~W}$ mercury UV lamp, where the organomercuries were digested to $\mathrm{Hg}^{2+}$ and further reduced to cold mercury vapour. Then by using argon as carrier gas, the mercury vapour generated in the reaction was separated in a gas-liquid separator and brought to the AFS (AF-610A, Beijing Raileigh Analytical Instrument Company) for determination.

The experimental conditions for the developed UV-CVG with formic acid in mobile phase as reaction reagent are listed in Table 1.

\subsection{Chemicals and reagents}

Stock solution of standard inorganic mercury $\left(1 \mathrm{mg} \mathrm{mL}^{-1}\right.$ as $\mathrm{Hg}$ ) was prepared by dissolving appropriate amount of $\mathrm{HgCl}_{2}$ ( $\geq 99.5 \%$, Beijing Chemical Factory, Beijing, China) in $5 \%$
Table 1

Operating conditions for the developed HPLC-AFS system

\begin{tabular}{|c|c|}
\hline Parameter & Optimized value \\
\hline \multicolumn{2}{|l|}{$\overline{\text { HPLC }}$} \\
\hline Column & $\begin{array}{l}\text { Shim-pack CLC-ODS (Shimadzu), } 15 \mathrm{~cm} \\
\text { length, } 6.0 \mathrm{~mm} \text { I.D., } 5 \mu \mathrm{m}\end{array}$ \\
\hline Mobile phase & $\begin{array}{l}\mathrm{A}: 3 \%(\mathrm{v} / \mathrm{v}) \mathrm{CH}_{3} \mathrm{CN}, 240 \mathrm{mmol} \mathrm{L}^{-1} \\
\mathrm{HCOONH}-\mathrm{HCOOH}(\mathrm{pH} 2.8), 0.01 \% \\
\text { 2-mercaptoethanol; B: } 30 \%(\mathrm{v} / \mathrm{v}) \mathrm{CH}_{3} \mathrm{CN} \text {, } \\
240 \text { mmol L }{ }^{-1} \mathrm{HCOONH}{ }_{4}-\mathrm{HCOOH}(\mathrm{pH} \\
2.8), 0.01 \% \text { 2-mercaptoethanol; } 0-11 \mathrm{~min}: \\
100 \% \text { A; } 11-12 \text { min: } 100 \% \mathrm{~A} \rightarrow 100 \% \mathrm{~B} \text {; } \\
12-30 \text { min: } 100 \% \mathrm{~B} ; 30-31 \text { min: } 100 \% \\
\text { B } \rightarrow 100 \% \text { A }\end{array}$ \\
\hline Flow rate of mobile phase & $1.4 \mathrm{~mL} \mathrm{~min}^{-1}$ \\
\hline Sample injection & $100 \mu \mathrm{L}$ \\
\hline \multicolumn{2}{|c|}{ UV digestion and vapour generation } \\
\hline Power of UV lamp & Mercury lamp, $20 \mathrm{~W}$ \\
\hline Reaction coil & $\begin{array}{l}\text { PTFE tube, } 0.5 \mathrm{~m} \text { length, } 0.8 \mathrm{~mm} \text { I.D., } \\
1.2 \mathrm{~mm} \text { O.D. }\end{array}$ \\
\hline \multicolumn{2}{|l|}{ AFS } \\
\hline Lamp & Mercury hollow cathode lamp, $253.7 \mathrm{~nm}$ \\
\hline PMT voltage & $280 \mathrm{~V}$ \\
\hline Primary current & $40 \mathrm{~mA}$ \\
\hline Carrier gas & $\mathrm{Ar}, 500 \mathrm{~mL} \mathrm{~min}^{-1}$ \\
\hline
\end{tabular}

(v/v) $\mathrm{HNO}_{3}$. Individual stock solutions of standard organomercury chloride $\left(1 \mathrm{mg} \mathrm{mL}^{-1}\right.$ as $\mathrm{Hg}$ ) were prepared by dissolving appropriate amounts of methylmercury chloride, ethylmercury chloride and phenylmercury chloride in methanol, respectively. All the organomercury compounds were purchased from Merck ( $\geq 98 \%$, Darmstadt, Germany). The mixture standard of mercury species for injection was diluted from bulk solution daily and was dissolved in $10 \mathrm{mmol} \mathrm{L}^{-1}$ sodium thiosulfate.

Analytical grade formic acid, ammonia solution and sodium thiosulfate, as well as GR grade sodium hydroxide, potassium hydroxide and hydrochloric acid were from Beijing Chemical Factory (Beijing, China). Methanol and acetonitrile were HPLC solvent (J.T. Baker, Phillipsburg, NJ, USA). All other chemicals were analytical grade.

Mobile phase and standard solutions were prepared with de-ionized water from a Barnstead ultra-pure water system (Barnstead International, Dubuque, IA, USA).

\subsection{Preparation of sample extracts}

Certified reference material DORM-2 (from Institute for National Measurement Standards, National Research Council of Canada) and seafood samples were prepared with an alkaline digestion method [8]. Briefly, into a $50 \mathrm{~mL}$ glass centrifuge tube was added accurately weighed lyophilized and ground sample $(\sim 0.2 \mathrm{~g})$ and $2 \mathrm{~mL} 25 \%(\mathrm{~m} / \mathrm{v}) \mathrm{KOH}$ (in methanol), and the tube was shaken overnight. Then, $6 \mathrm{~mL}$ of $\mathrm{CH}_{2} \mathrm{Cl}_{2}$ was added, and the solution was titrated by $1.5 \mathrm{~mL}$ concentrated $\mathrm{HCl}$. The resulting solution was shaken for $15 \mathrm{~min}$. After centrifuging at $3000 \mathrm{rpm}$ for $15 \mathrm{~min}$, the $\mathrm{CH}_{2} \mathrm{Cl}_{2}$ phase was accurately transferred into a $10 \mathrm{~mL}$ glass centrifuge tube and $1 \mathrm{~mL}$ of $10 \mathrm{mmol} \mathrm{L}^{-1}$ sodium thiosulfate was added. The mixture was shaken for $45 \mathrm{~min}$. 
After centrifuging at $3500 \mathrm{rpm}$ for $15 \mathrm{~min}$, the water phase was taken as sample for the determination of organomercuries by HPLC-AFS.

\section{Results and discussion}

\subsection{Effect of mobile phase $\mathrm{pH}$}

$\mathrm{HCOONH}_{4}-\mathrm{HCOOH}$ buffer was adopted in the chromatographic separation. Keeping the concentration of formate at $300 \mathrm{mmol} \mathrm{L}^{-1}$, the $\mathrm{pH}$ of mobile phase was investigated in the range from 2.0 to 3.0. Mobile phase with $\mathrm{pH} 2.8$ was found have relatively high sensitivities for detection and appropriate buffer capacity. Therefore, a mobile phase with $\mathrm{pH} 2.8$ was used for further experiments. The elution order of four mercury species is $\mathrm{MeHg}$, inorganic mercury, EtHg and $\mathrm{PhHg}$. Both inorganic mercury and $\mathrm{MeHg}$ can form complex with 2-mercaptoethanol (ME) in mobile phase. $\mathrm{Hg}(\mathrm{II})$ and $\mathrm{MeHg}$ bind with two and one molecule of 2-mercaptoethanol to form complexes of $\mathrm{Hg}(\mathrm{II})-(\mathrm{ME})_{2}$ and $\mathrm{MeHg}-\mathrm{ME}$, respectively. $\mathrm{Hg}$ (II)-(ME) $)_{2}$ is more hydrophobic than $\mathrm{MeHg}-\mathrm{ME}$ and has longer retention time on a $\mathrm{C} 18$ column. Therefore, inorganic mercury elutes after $\mathrm{MeHg}$. Lower sensitivity was observed for $\mathrm{Hg}$ (II) than other organomercurial species in this UV-CVG system. Similar phenomena were observed in UV-CVG system with formic acid [24] and mercaptoethanol [26]. The reason is not known and further investigation is required to elucidate these phenomena.

\subsection{Effect of formate concentration}

The influence of formate concentration on the separation and detection of mercury species was studied in the range of $0-420 \mathrm{mmol} \mathrm{L}^{-1}$, and the results were shown in Fig. 1. With no formate in the mobile phase, the four mercury species still can be detected with low sensitivity. This perhaps can be ascribed to

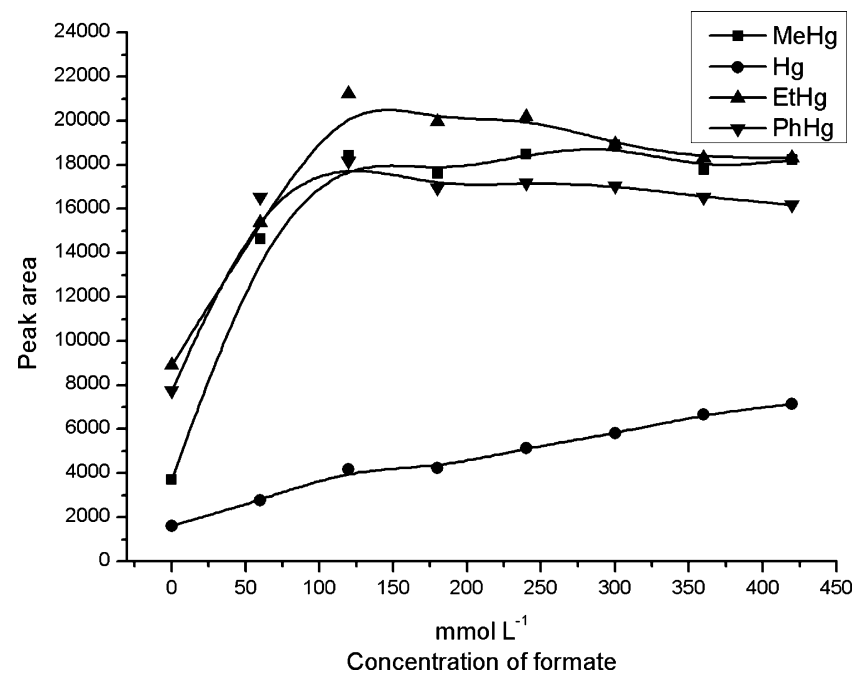

Fig. 1. Effect of formate concentration on the fluorescence intensities of mercury compounds. $\mathrm{pH}$ of mobile phase: 2.8 . Length of PTFE reaction coil: $1.0 \mathrm{~m}$. Flow rate of mobile phase: $1.2 \mathrm{~mL} \mathrm{~min}^{-1}$. Concentration of mercury species: $100 \mu \mathrm{g} \mathrm{L}^{-1}$. Other conditions were given in Table 1. the generation of mercury vapour resulted from the UV irradiation of mercaptoethanol [26]. The signal intensity of inorganic mercury increased with the increasing of formate concentration, while the sensitivity of organic mercury species increased firstly and then decreased slightly. Considering the sensitivities of four mercury species, a formate concentration of $240 \mathrm{mmol} \mathrm{L}^{-1}$ was selected as a compromise.

\subsection{Effect of mobile phase flow rate}

The influence of mobile phase flow rate on separation was investigated in the range from 0.8 to $1.4 \mathrm{~mL} \mathrm{~min}^{-1}$, with the gradient program shown in Table 1. When the mobile phase flow rate was lower than $1.2 \mathrm{~mL} \mathrm{~min}^{-1}$, the signal intensities of mercury species were low and $\mathrm{MeHg}$ cannot be separated from inorganic mercury effectively. With a mobile phase flow rate of $1.4 \mathrm{~mL} \mathrm{~min}^{-1}$, baseline separation of four mercury species was achieved in $30 \mathrm{~min}$ with acceptable column pressure (130 bar). Therefore, a flow rate of $1.4 \mathrm{~mL} \mathrm{~min}^{-1}$ was employed for later research.

\subsection{Effect of length of PTFE reaction coil}

Fig. 2 shows the influence of the length of PTFE reaction coil on the signal intensities of mercury species. For all the mercury species except for EtHg, the signal intensities increased with the reaction coil length in the range of $0.25-0.5 \mathrm{~m}$. By using a $0.25 \mathrm{~m}$ PTFE reaction coil, the signal intensities were low, owning to the insufficient conversion efficiencies of organomercuries or $\mathrm{Hg}^{2+}$ to $\mathrm{Hg}^{0}$. With a PTFE reaction coil longer than $0.5 \mathrm{~m}$, the signal intensities decreased due to further photo-oxidation of $\mathrm{Hg}^{0}$ [27]. For EtHg, however, the signal intensity decreased with the reaction coil length in the entire studied range, which might suggest $\mathrm{EtHg}$ is more easily conversed to $\mathrm{Hg}^{2+}$ than the other species. Accordingly, in the following study, a $0.5 \mathrm{~m}$ PTFE tube as the reaction coil was employed to achieve maximum signal intensities for analyte. The irradiation time was about $11 \mathrm{~s}$, as

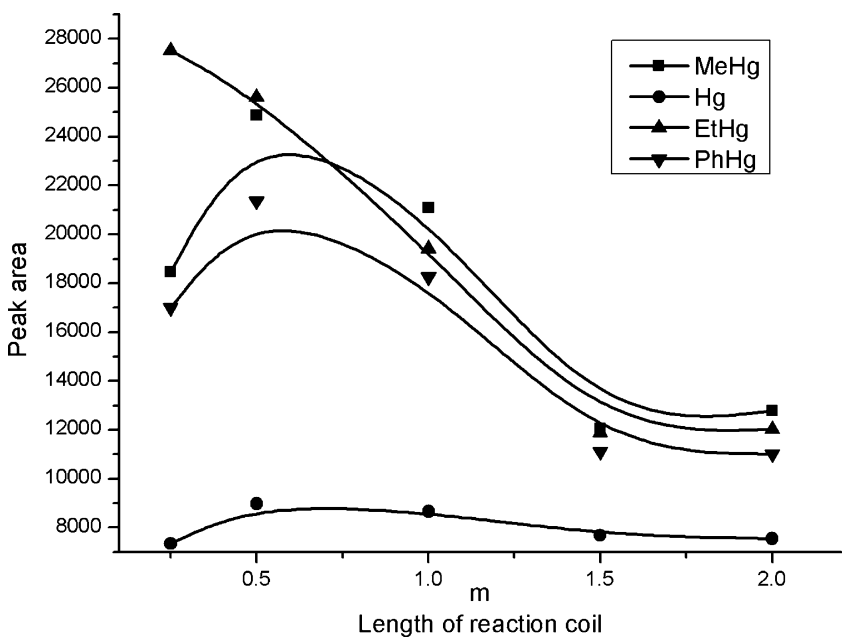

Fig. 2. Effect of length of PTFE reaction coil on the fluorescence intensities of mercury compounds. Concentration of mercury species: $100 \mu \mathrm{g} \mathrm{L}^{-1}$. Other conditions were given in Table 1 . 


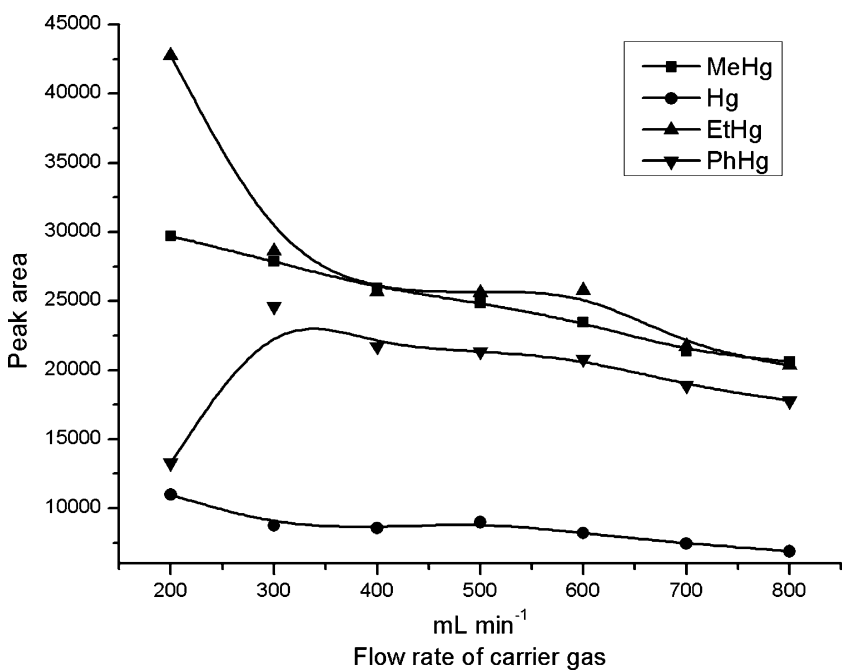

Fig. 3. Effect of carrier gas flow rate on the fluorescence intensities of mercury compounds. Concentration of mercury species: $100 \mu \mathrm{g} \mathrm{L}^{-1}$. Other conditions were given in Table 1.

calculated from the flow rate and the inner volume of the PTFE reaction coil. The shorter reaction time than post-column mix [24] perhaps ascribed to a higher energy mercury UV lamp used.

\subsection{Effect of carrier gas flow rate}

The effect of argon gas flow rate on signal intensities of mercury species was studied in the range of $200-800 \mathrm{~mL} \mathrm{~L}^{-1}$ (Fig. 3). The baseline noise was very high when the flow rate of argon gas was lower than $300 \mathrm{~mL} \mathrm{~min}^{-1}$. Better baseline was observed with the increase of argon gas flow. However, the signal intensity decreased slowly with the flow rate of argon gas increasing. Low baseline noise and satisfactory signal intensities of mercury species were obtained at an argon carrier gas flow rate of $500 \mathrm{~mL} \mathrm{~min}^{-1}$, which was chosen in the following study.

\subsection{Effect of $\mathrm{Na}_{2} \mathrm{~S}_{2} \mathrm{O}_{3}$ in sample matrix}

Since the final sample for injection contained $10 \mathrm{mmol} \mathrm{L}^{-1}$ $\mathrm{Na}_{2} \mathrm{~S}_{2} \mathrm{O}_{3}$, the influence of $\mathrm{Na}_{2} \mathrm{~S}_{2} \mathrm{O}_{3}$ in sample matrix on separation and detection was investigated. The result revealed that with the addition of $\mathrm{Na}_{2} \mathrm{~S}_{2} \mathrm{O}_{3}$ in the sample, the resolution of $\mathrm{MeHg}$ and inorganic mercury was improved and signal intensities of mercury species increased. The improvement of sensitivity was possibly induced by on-column concentration. $\mathrm{Na}_{2} \mathrm{~S}_{2} \mathrm{O}_{3}$ can form water soluble complex with organic or inorganic mercury

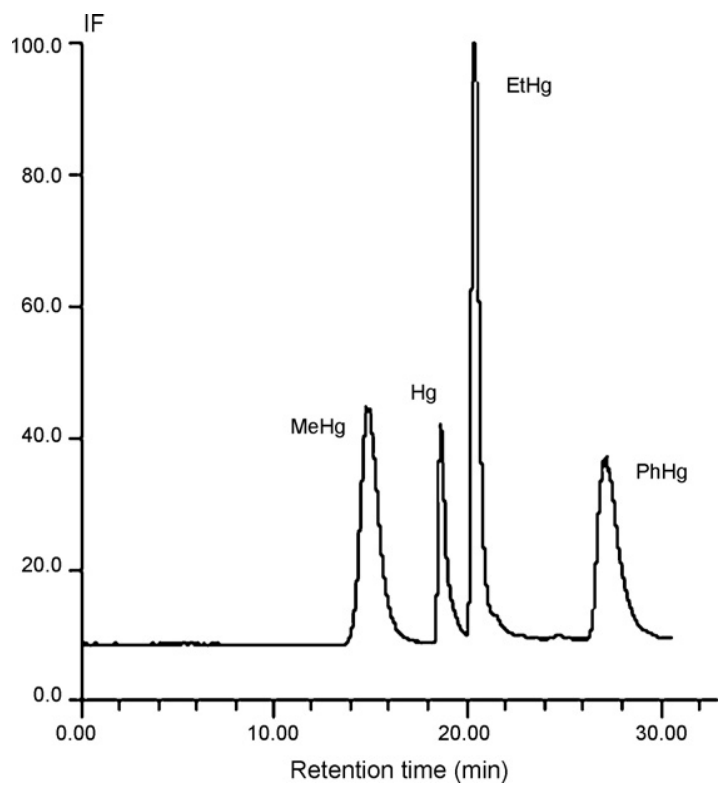

Fig. 4. Chromatogram of four mercury species using the developed HPLC-UVCVG-AFS system. Concentration of mercury species: $10 \mu \mathrm{g} \mathrm{L}^{-1}$. Experimental conditions were given in Table 1.

species, which is weakly retained on a C18 column. When the injected sample was mixed with the mobile phase, however, 2mercaptoethanol competed with $\mathrm{Na}_{2} \mathrm{~S}_{2} \mathrm{O}_{3}$ for binding mercury species to form mercury-mercaptoethanol complex, which is retained on a $\mathrm{C} 18$ column more strongly than $\mathrm{Na}_{2} \mathrm{~S}_{2} \mathrm{O}_{3}-$ mercury complex. Therefore, the migration velocity of mercury species was decreased which induced on-column stacking. Another advantage of the addition of $\mathrm{Na}_{2} \mathrm{~S}_{2} \mathrm{O}_{3}$ in sample is that it avoided the adsorption of mercury species on the injection loop. The separation and signal intensities of mercury species have no apparent change when the $\mathrm{Na}_{2} \mathrm{~S}_{2} \mathrm{O}_{3}$ concentration was varied from 2 to $12 \mathrm{mmol} \mathrm{L}^{-1}$. Considering that the final sample for injection contained $10 \mathrm{mmol} \mathrm{L}^{-1} \mathrm{Na}_{2} \mathrm{~S}_{2} \mathrm{O}_{3}$, all standard solution for injection was prepared in $10 \mathrm{mmol} \mathrm{L}^{-1} \mathrm{Na}_{2} \mathrm{~S}_{2} \mathrm{O}_{3}$.

\subsection{Analytical performance}

Fig. 4 shows the typical chromatogram of $\mathrm{MeHg}, \mathrm{Hg}$, EtHg and $\mathrm{PhHg}$ standards at $10 \mu \mathrm{gL}^{-1}$ levels, obtained with the optimized conditions. Table 2 shows the analytical features of the proposed method under optimized conditions. The detection limits based on three levels of the background were $0.033 \mu \mathrm{g} \mathrm{L}^{-1}$ for $\mathrm{MeHg}, 0.085 \mu \mathrm{g} \mathrm{L}^{-1}$ for $\mathrm{Hg}, 0.029 \mu \mathrm{g} \mathrm{L}^{-1}$

Table 2

Analytical performance of the developed HPLC-AFS system

\begin{tabular}{|c|c|c|c|c|c|}
\hline Compound & Calibration curve $^{\mathrm{a}}$ & Relation coefficient & Detection limit $\left(\mu g \mathrm{~L}^{-1}\right)$ & $\operatorname{RSD}(\%)^{\mathrm{b}}$ & Recovery $(\%)^{\mathrm{c}}$ \\
\hline $\mathrm{MeHg}$ & $Y=261.4 X-646.3$ & 0.9990 & 0.033 & 1.7 & 103 \\
\hline $\mathrm{Hg}(\mathrm{II})$ & $Y=86.1 X-50.6$ & 0.9975 & 0.085 & 4.6 & - \\
\hline $\mathrm{EtHg}$ & $Y=265.1 X-454.4$ & 0.9988 & 0.029 & 1.9 & 87.1 \\
\hline $\mathrm{PhHg}$ & $Y=227.6 X-816.6$ & 0.9969 & 0.038 & 2.2 & 74.9 \\
\hline
\end{tabular}

\footnotetext{
a $Y$, peak area; $X$, concentration $\left(\mu \mathrm{g} \mathrm{L}^{-1}\right)$.

b Standard concentration, $20 \mu \mathrm{g} \mathrm{L}^{-1}, n=3$.

c Recovery for spiking with $20 \mathrm{ng}$ (as $\mathrm{Hg}$ ) of each individual mercury species.
} 
Table 3

Comparison of method detection limits for mercury speciation using various HPLC-hyphenated techniques

\begin{tabular}{lccccl}
\hline & \multicolumn{3}{c}{ Detection limits (as Hg, pg) } & Reference \\
\cline { 2 - 6 } & MeHg & EtHg & PhHg & Hg(II) & \\
\hline HPLC-CV-AFS & 3.3 & 2.9 & 3.8 & 8.5 & This work \\
HPLC-CV-AFS & 16.2 & 4.0 & 17.4 & 20.2 & {$[24]$} \\
HPLC-CV-AFS & 200 & 170 & 140 & 300 & {$[8]$} \\
HPLC-CV-AFS & 27 & 26 & 21 & 19 & {$[9]$} \\
HPLC-CV-AFS & 8 & 10 & 10 & 10 & {$[11]$} \\
HPLC-CV-AFS & 18 & 18 & 20 & 16 & {$[12]$} \\
HPLC-CV-AFS & 10 & - & - & - & {$[14]$} \\
HPLC-CV-ICP-MS & 6 & 5 & - & 9 & {$[6]$} \\
HPLC-USN-ICP-MS & 140 & 160 & - & 80 & {$[28]$} \\
HPLC-ICP-MS & 1.6 & - & - & 1.0 & {$[29]$} \\
HPLC-CV-AAS & 80 & 80 & 80 & 80 & {$[7]$} \\
HPLC-CV-MIP-AES & 35 & - & - & 15 & {$[15]$} \\
\hline
\end{tabular}

for EtHg and $0.038 \mu \mathrm{g} \mathrm{L}^{-1}$ for $\mathrm{PhHg}$, which correspond to an absolute detection limit of 3.3, 8.5, 2.9 and $3.8 \mathrm{pg}$ (as $\mathrm{Hg}$ ), respectively. A comparison of the detection limits obtained by other HPLC-hyphenated techniques for mercury speciation is given in Table 3. The detection limits of the present method are comparable with other HPLC-hyphenated techniques. The recoveries of the spikes of each organomercurial species of seafood sample ranged from 74.9 to $103 \%$. The relatively lower recoveries of $\mathrm{EtHg}$ and $\mathrm{PhHg}$ might be ascribed to the dealkylation during extraction [30].

\subsection{Validation of the method and application}

In order to validate the method developed in the present study, $\mathrm{MeHg}$ content in certified reference material DORM-2 (dogfish muscle) was determined. As shown in Table 4, the determined result was in good agreement with the certified value. The proposed method was also applied to determine $\mathrm{MeHg}$ in seafood collected from Yantai port, Shandong Province of China, and results were also shown in Table 4. These results indicate that the developed method is applicable for the determination of $\mathrm{MeHg}$ in biological samples.

Table 4

Results of MeHg contents in DORM-2 and seafood samples

\begin{tabular}{lcc}
\hline Sample & $\begin{array}{l}\mathrm{MeHg} \text { concentration } \\
\left(\mathrm{mean}^{\mathrm{a}} \pm \mathrm{SD}^{\mathrm{b}},\right. \\
\left.\mathrm{ng} \mathrm{g}^{-1}\right)\end{array}$ & $\begin{array}{l}\text { Certified value } \\
\left(\mathrm{mean}^{\mathrm{b}} \mathrm{SD}^{\mathrm{b}},\right. \\
\left.\mathrm{ng} \mathrm{g}^{-1}\right)\end{array}$ \\
\hline $\begin{array}{c}\text { DORM-2 } \\
\begin{array}{l}\text { Ruditapes philippinarum } \\
\text { (Yantai) }\end{array}\end{array}$ & $\begin{array}{c}4.19 \times 10^{3} \pm 0.07 \times 10^{3} \\
4470 \pm 320 \\
\begin{array}{l}\text { Sinonovacula constricta } \\
\text { (Yantai) }\end{array}\end{array}$ & - \\
$\begin{array}{l}\text { Neverita didyma } \text { (Yantai) } \\
\text { Saxidomus purpuratus } \\
\text { (Yantai) }\end{array}$ & $33.2 \pm 3.0$ & - \\
$\begin{array}{l}\text { Scapharca subcrenata } \\
\text { (Yantai) }\end{array}$ & $71.1 \pm 1.7$ & - \\
\hline $\begin{array}{l}\text { a } n=3 . \\
\text { b Standard deviation. }\end{array}$ & $16.8 \pm 1.1$ & - \\
\hline
\end{tabular}

\section{Conclusions}

A novel photo-induced chemical vapour generation method with formic acid in mobile phase was developed as interface of HPLC-AFS hyphenated system for the speciation of inorganic mercury, $\mathrm{MeHg}, \mathrm{EtHg}$ and $\mathrm{PhHg}$. In the developed hyphenated systems, formic acid in mobile phase was used as reaction reagent for UV-CVG, therefore no other post-column reaction reagent and pump system were needed, which simplified instrumentation and decreased analytical cost significantly.

The developed UV-CVG system with formic acid in mobile phase as reaction reagent was expected to be applicable in speciation of other organometallic compounds. Also, the novel CVG system developed could be applied as interface for HPLC with other analytical atomic spectrometric techniques. Moreover, other energy irradiations besides UV, such as microwave [8], heat [31] and supersonic energy [31,32] were also expected to be applied in the hyphenated system based on CVG with formic acid.

\section{Acknowledgment}

This work was supported by the National Natural Science Foundation of China (20621703 and 20577057).

\section{References}

[1] R.E. Sturgeon, X. Guo, Z. Mester, Anal. Bioanal. Chem. 382 (2005) 881.

[2] S. Río-Segade, C. Bendicho, Talanta 48 (1999) 477.

[3] C. Sarzanini, G. Sacchero, M. Aceto, O. Abollino, E. Mentasti, Anal. Chim. Acta 284 (1994) 661.

[4] E. Munaf, H. Haraguchi, D. Ishii, T. Takeuchi, M. Goto, Anal. Chim. Acta 235 (1990) 399.

[5] R. Clough, S.T. Belt, B. Fairman, T. Catterick, E.H. Evans, J. Anal. At. Spectrom. 20 (2005) 1072.

[6] C. Chiou, S. Jiang, K.S.K. Danadurai, Spectrochim. Acta B 56 (2001) 1133.

[7] R. Falter, H.F. Schöler, J. Chromatogr. A 675 (1994) 253.

[8] L. Liang, G. Jiang, J. Liu, J. Hu, Anal. Chim. Acta 477 (2003) 131.

[9] Y. Li, X. Yan, L. Dong, S. Wang, Y. Jiang, D. Jiang, J. Anal. At. Spectrom. 20 (2005) 467

[10] H. Hintelmann, R.D. Wilken, Appl. Organomet. Chem. 7 (1993) 173.

[11] R. Falter, G. Ilgen, Fresenius J. Anal. Chem. 358 (1997) 407.

[12] E. Bramanti, C. Lomonte, M. Onor, R. Zamboni, A. D’Ulivo, G. Raspi, Talanta 66 (2005) 762.

[13] E. Ramalhosa, S.R. Segade, E. Pereira, C. Vale, A. Duarte, Analyst 126 (2001) 1583.

[14] E. Ramalhosa, S.R. Segade, E. Pereira, C. Vale, A. Duarte, Anal. Chim. Acta 448 (2001) 135.

[15] J.M. Costa-Fernández, F. Lunzer, R. Pereiro-García, A. Sanz-Medel, N. Bordel-García, J. Anal. At. Spectrom. 10 (1995) 1019.

[16] K. Kawano, M. Komatsu, Y. Yajima, H. Haneda, H. Maki, T. Yamamoto, Appl. Surf. Sci. 189 (2002) 265.

[17] X. Wang, S.O. Pehkonen, A.K. Ray, Electrochim. Acta 49 (2004) 1435.

[18] V.N.H. Nguyen, D. Beydoun, R. Amal, J. Photochem. Photobiol. A: Chem. 171 (2005) 113.

[19] P. Mytych, A. Karocki, Z. Stasicka, J. Photochem. Photobiol. A: Chem. 160 (2003) 163.

[20] X. Guo, R.E. Sturgeon, Z. Mester, G.J. Gardner, Anal. Chem. 75 (2003) 2092.

[21] X. Guo, R.E. Sturgeon, Z. Mester, G.J. Gardner, Anal. Chem. 76 (2004) 2401.

[22] Y.C. Sun, Y.C. Chang, C.K. Su, Anal. Chem. 78 (2006) 2640.

[23] Y. Yin, J. Liang, L. Yang, Q. Wang, J. Anal. At. Spectrom. 22 (2007) 330. 
[24] Y. Yin, J. Liu, B. He, E. Gao, G. Jiang, J. Anal. At. Spectrom. 22 (2007) 822.

[25] C. Zheng, Y. Li, Y. He, Q. Ma, X. Hou, J. Anal. At. Spectrom. 20 (2005) 746.

[26] Y. Yin, J. Qiu, L. Yang, Q. Wang, Anal. Bioanal. Chem. 388 (2007) 831.

[27] J.D. Lalonde, M. Amyot, A.L. Kraepiel, F.M.M. Morel, Environ. Sci. Technol. 35 (2001) 1367.
[28] C. Huang, S. Jiang, J. Anal. At. Spectrom. 8 (1993) 681.

[29] B. Vallant, R. Kadnar, W. Goessler, J. Anal. At. Spectrom. 22 (2007) 322

[30] S.C. Hight, J. Cheng, Anal. Chim. Acta 567 (2006) 160.

[31] A.S. Ribeiro, M.A. Vieira, S. Willie, R.E. Sturgeon, Anal. Bioanal. Chem. 388 (2007) 849

[32] S. Gil, I. Lavilla, C. Bendicho, Anal. Chem. 78 (2006) 6260 